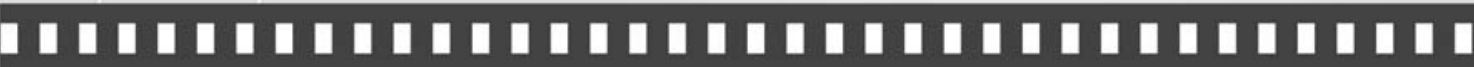

\author{
A encruvilhada do fotojornalismo
}

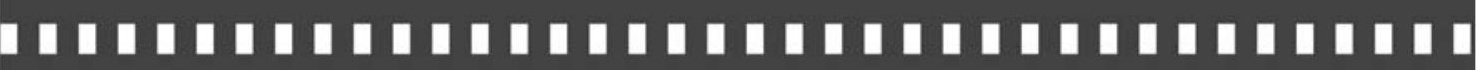

Simonetta Persichetti 


\title{
A encruzilhada do fotojornalismo
} The crossroad of photojournalism

\author{
Simonetta Persichetti*
}

\begin{abstract}
Resumo: Este artigo trata da crise do fotojornalismo, desencadeada a partir dos anos 1980, e os debates acadêmicos que permeiam esta discussão. Questiona e sugere como enfrentar as novas formas de informação: o novo fotojornalismo, a espetacularização da notícia e da fotografia, o jornalismo cidadão e a enxurrada de imagens produzidas pelas câmeras digitais amadoras, que aos poucos vão ocupando espaços na mídia.
\end{abstract}

Palavras-chave: jornalismo; fotojornalismo; crise do fotojornalismo; espetacularização.

\begin{abstract}
This article features the crisis of photojournalism, sparked in the eighties, and the academic debates aroused by this discussion. It points out the key issues and offer suggestions on how to cope with new information: the new photojournalism, the spectacularization of the news and photography, citizenship journalism and the flood of images produced by amateur digital equipments, which steadily spread throughout the media.
\end{abstract}

Key-words: journalism; photojournalism; crisis of photojournalism; spectacularization.

\footnotetext{
*Jornalista. Mestre em Comunicação e Artes. Doutora em Psicologia Social. Autora dos livros Imagens da Fotografia Brasileira I e Imagens da Fotografia Brasileira II. Organiza a Coleção Senac de Fotografia. Docente do Curso de Especialização em Fotografia da Universidade Estadual de Londrina. Membro do Conselho Editorial da revista Discursos Fotográficos.
} 


\section{Introdução}

Já faz alguns anos que o fotojornalismo está em discussão. Teóricos predizem a morte desta linguagem, outros defendem suas transformações.

A verdade é que há muito tempo um tema fotográfico não era alvo de disputas tão acirradas. Embora o Brasil ainda não siga esta tradição, no resto do mundo e especialmente na Europa este tema tem ocasionado várias publicações e textos analíticos.

Como definir o fotojornalismo hoje? Ele ainda existe? Morreu? Ou estamos em uma encruzilhada e devemos repensar sua função, sua estética, e pior, sua utilidade.

Alguns teóricos há mais tempo, outros mais recentemente, têm se debruçado sobre este tema:

[....] quem precisa dos fotojornalistas e dos filtros a que estão submetidos? Será que estamos frente ao desaparecimento da neutralidade objetiva da fotografia outorgada pelos meios de comunicação? Ou estamos enfrentando algo de novo que vai além do real fotográfico, estamos diante da contestação incontestável da subjetividade, que somado ao conjunto é a realidade em si mesma. ${ }^{1}$ (MARZO, 2006, p.8).

\section{Fotojornalismo: ficção ou não ficção?}

Um livro recente - Photojournalisme, à la croisée de chemins é bastante radical e crítico em relação ao fotojornalismo. Para os autores, o “mito do fotojornalismo está morto”. A responsabilidade da informação foi esquecida e cada vez mais estamos entregues às imagens sensacionalistas ou espetaculares. A passagem do artesanal para a indústria - entenda-se aqui do analógico ao digital - foi mortal. Nem tanto. Estas afirmações tão

${ }^{1}$ Tradução livre da autora. 
radicais e violentas na verdade escondem o medo do novo: "Cabe ao fotojornalismo reinventar seu futuro para continuar a contar o mundo.”2 (COLO; ESTÈVE; JACOB, 2005, p.5).

Estamos frente sim a uma revolução visual, a uma nova modalidade de produzir e consumir imagens, mas a morte do fotojornalismo não pode ser creditada à tecnologia e sim à falta de interesse de editores e fotógrafos em sair do convencional, do fotografável, do "óbvio eficiente" como gosta de lembrar o fotógrafo Hélio Campos Mello³.

Bom, estamos diante de dois momentos diferentes do fotojornalismo. De um lado, uma geração que teve na fotografia das grandes revistas ilustradas como Life e Paris Match sua inspiração. O lema da Paris Match, criada em 1949, era: “o peso das palavras, o choque das imagens”. De outro, uma estética mais próxima da ilustração do que da informação.

Relembrando a história do fotojornalismo moderno, ele se inicia na Alemanha em 1930 pelas mãos do Erich Salomon:

Os foto-repórteres modernos nasceram verdadeiramente nos anos vinte, sendo notáveis os nomes de Erich Salomon (18861944) e Felix H. Man (1893-1985), bem como uma série de imigrantes húngaros na Europa que contribuíram para trazer aportações originiais ao médium fotográfico: Lászlo Moholy-Nagy (1895-1946) tornava-se um dos mestres da Bauhaus; Martin Munkacsi (1896-1963) chegava em Berlim , em 1927; André Kertész (1894-1985) e Brassaï (1899-1984) tingiram Paris, entre 1924 e 1925. (SOUSA, 2000, p.72).

Ele inicia uma nova fase da fotografia da imprensa: a imagem que cria o acontecimento e não mais auxilia ou ilustra um texto. A imagem fotográfica criada ou construída a partir de uma ideologia existente:

${ }^{2}$ Tradução livre do original: “C'est a lui d'inventer som avenir pour continuer à raconter le monde."

${ }^{3}$ Ver referências. 
Jornais e revistas aproveitam as fotos para melhorar o aspecto gráfico ou informarem melhor, obrigando fotojornalistas a pensarem nas fotografias, tornando comuns as seqüências fotográficas, as foto-reportagens e os foto-ensaios. Alguns fotógrafos esforçavam-se mesmo por mostrar o quotidiano mais prosaico, como fez Kértesz com os camponeses bretões. (SOUSA, 2000, p.84).

Não podemos esquecer de outro momento importante do fotojornalismo mundial, que foi a criação nos Estados Unidos da revista Life, em 1936, que se tornou lenda dentro do jornalismo. Ela, que durou até o início dos anos 70, reiterou a idéia do fotojornalismo como um jornalismo de guerra, visto que o período de sua duração coincide com grandes conflitos da Humanidade: Guerra Civil Espanhola, Segunda Guerra Mundial, os conflitos na África, e finalmente a Guerra do Vietnã.

Mesmo a famosa Magnum é de 1947, portanto já do pós-guerra, momentos em que imagens ou matérias feitas por Cartier-Bresson, Robert Capa, Eugene Smith formavam o imaginário dos fotojornalistas. É famosa a frase de Robert Capa: "Se a sua foto não ficou boa é porque você não chegou perto o suficiente."

A grande reportagem tomava conta das revistas: uma história era contada por várias imagens, privilegiava-se o trabalho do fotógrafo como “contador de histórias”. A imprensa investia nisso. E aqui entra também o Brasil. O fotojornalismo no Brasil, entendido como uma linguagem, começou também no final dos anos 40, mais precisamente com Jean Manzon na revista $O$ Cruzeiro. Mais tarde se perpetuou em revistas como Manchete, nos anos 50, e Realidade, nos anos 60. Não à toa, esses anos são considerados a época de ouro do fotojornalismo brasileiro.

A fotografia sobressaía e de alguma maneira o choque, o impacto ia se instaurando na imprensa. Construção de imagens que querem, além de mostrar o horror, fazer-nos dele participar.

Nos anos 70, Roland Barthes escreveu um texto sobre a fotografiachoque. Imagens carregadas de sentidos que não deixam refletir, julgar ou pensar por nós mesmos.Segundo Barthes, é por isso que elas se tornam 
"falsas": "muito construídas para serem fotografia, muito perfeitas para serem pintura".

É uma fotografia que cria o escândalo do horror, mas não cria em nós o sentimento do horror:

A maior parte das fotografias-choque que nós vimos são falsas já que escolheram um ponto intermediário entre o factual e o factual aumentado: muito intencionais para serem fotografias e muito exatas para se passarem por pintura, perdem necessariamente, a um só momento, o escândalo da letra e a verdade da arte: quiseram crias signos puros, sem dar a estes signos a ambiguidade, ou o atraso de um espessor. ${ }^{4}$ (BARTHES apud MARRA, 2001, p.44).

Nos anos 80, pode-se acompanhar o surgimento de outro tipo de fotojornalismo: o engajado, o ideológico. Nele, o fotógrafo toma posição descaradamente. No Brasil, fruto também do surgimento das agências, encontra-se a famosa briga entre a teleobjetiva e a grande angular. São momentos de censura nos quais a fotografia é a única maneira de expressar por meio da imprensa.

Os anos 90 são o momento do declínio do fotojornalismo mundial. Ele deixa de ser engajado, jornalístico, e assume uma estética publicitária ou cinematográfica, que faz parte dos anos 90 e do início do novo século. A fotografia de imprensa retorna ao seu lugar de meramente ilustrativa. Não é mais o impacto da imagem ou o horror que interessam, mas luzes e sombras, a dramaticidade construída por uma estética vazia. Não existe mais a fotografia de guerra, existe o drama: a viúva jogada por sobre o corpo do marido, a mãe madonna que chora o filho, camponeses com o olhar perdido frente às suas casas levadas pela enchente ou pelo terremoto. Um drama estético que, se aparentemente quer substituir a foto-choque, na verdade se presta ao mesmo papel. Ou seja, comove, mas não informa.

\footnotetext{
${ }^{4}$ Tradução livre do original: "La maggior parte delle fotografie-choc che ci sono mostrate sono false in quanto appunto hanno scelto uno stato intermediario tra il fatto letterale e il fatto maggiorato: troppo intenzionali per essere fotografie e troppo estate per essere pittura, perdono necessariamente, a un tempo lo scandalo della lettera e la veritá dell'arte: si é voluto fare segni puri, senza risolversi a dare almeno a questi segni l'ambiguitá, il ritardo di uno spessore.”
} 
É bela, mas não é jornalismo. Como qualquer outra, é um discurso construído, falso, fazendo crer na imediatez do fato ou na não manipulação da imagem:

A discussão sobre os meios de comunicação nos leva ao uso político da imagem. As fotografias servem para construir fatos. Muitas imagens foram feitas por fotojornalistas, mas por motivos muitos e diversos, só algumas destas imagens se tornaram públicas, a imagem de um evento. Estas fotografias, se trasformaram no próprio evento, são monumentos. ${ }^{5}$ (D’AUTILIA, 2005, p.55).

\section{Fotojornalismo, um novo momento}

Nas imagens jornalísticas dos últimos anos encontraremos uma estética que se casa bem com nossa época. A mesma estética do espetáculo (conceito cunhado por Guy Debord, no final dos anos 60) encontrada no cinema e na televisão: "Tudo que era vivido diretamente tornou-se uma representação.” (DEBORD, 1997, p.13).

Há alguns anos, mais precisamente no final dos anos 90 criei alguns “inimigos" ao afirmar categoricamente que o fotojornalismo havia morrido. Continuo pensando da mesma maneira. Não sumiu a foto da imprensa, mas sumiu o conceito de informar por imagem. Temos uma imprensa baseada no personalismo, na foto posada, deixamos de ter a ação. Embora a tecnologia nos permita fazer coisas impensáveis, é nossa cabeça que não pensa. A fotografia que vai na capa do jornal não é a mais informativa ou importante; é a mais "bonita”:

\footnotetext{
${ }^{5}$ Tradução livre do original: "Il discorso sui media ci porta anche al problema dell'uso politico dell'immagine: le immagini servono a construire fatti. Molte immagini sono state prodotte dai fotoreporter, ma - per motivi vari e diversi - solo una parte di esse é diventata immagine pubblica, l'immagine pubblica di un enveto. Queste fotografie sono diventate delle dimostrazioni, hanno creato la coscienza colletiva di un evento, sono monumenti."
} 
De resto, uma fotografia-simbolo, na maioria das vezes não é verdadeira, é uma reconstrução, e já que é percebida só emotivamente, a sua perfeita adesão à realidade não interessa nem aos seus difusores nem aos seus fruidores. ${ }^{6}$ (D'AUTILIA, 2005, p.60).

Não gostaria que, ao retornar ao tema da discussão, o deadline seja desculpa (já que sempre existiu) para a produção de fotografias insípidas e sem eficiência. E aqui não estou falando de fotografias mal elaboradas ou equacionadas tecnicamente, mas de imagens que não dizem nada. Que não vão sobreviver. São imagens-espetáculos, pelas quais esquecemos que toda realidade é construída. Portanto, ficção.

Claro que não podemos ficar no discurso do passado e sim entender essa nova iconografia publicada na imprensa. Mas acho que o erro está em ver essa nova imagem com os olhos do passado e tentar equipará-la. Não é. O jornalismo está mudando, o fotojornalismo também. E aqui não podemos nos esquecer do digital, e da rapidez com a qual a informação está se espalhando, dificultando o impacto e a novidade.

Outro conceito que anda se espalhando rapidamente é o de que hoje todo mundo fotografa. Ora, na verdade, o mundo sempre fotografou tudo o tempo inteiro. O que acontece hoje é a circulação mais rápida destas imagens pelos vários blogs, sites, albuns digitais, etc.

A migração da fotografia analógica para digital supõe uma verdadeira revolução no tempo de recepção, que tem efeitos diretos sobre uma nova concepção do valor de uma imagem. A incorporação das tecnologias digitais supõe a passagem da relação temporal da fotografia com a realidade a uma relação temporal baseada exclusivamente no tempo de sua distribuição e na eliminação das barreiras do espaço. (VILCHES, 2006, p.161).

\footnotetext{
${ }^{6}$ Tradução livre do original: "Del resto una fotografia-simbolo, spesso non è vera, è una ricostruzione, e - poiché viene percepita emotivamente - la sua perfetta aderenza alla realitá non interessa né ai diffusori né ai fruitori.”
} 
Em relação ao fotojornalismo estamos assistindo a um fenômeno críticado por uns, apoiados por outros que é o “jornalista-cidadão”. O termo é horroroso, mas mostra bem a quantidade de pessoas fotografando o que se passa ao nosso redor. Fenômeno este que também já havia sido previsto por Debord (1997, p.14): "O espetáculo não é um conjunto de imagens, mas uma relação social entre pessoas, mediada por imagens.”

No Brasil, o jornal O Estado de S.Paulo foi o primeiro a adotar este processo, seguido depois pelo portal Terra e pelo jornal O Globo. O fato em si não é novo. Desde sempre fotografias de alguns acontecimentos, especialmente os trágicos, foram registradas antes por amadores e em seguida por profissionais. Talvez, anteriormente ninguém tinha se dado ao trabalho de discutir este assunto. Foi a nova tecnologia que o trouxe à baila. $\mathrm{O}$ fotógrafo e editor Pedro Meyer dedicou um editorial sobre o assunto em seu site Zonezero:

Como muitos se lembram, as primeiras e mais importantes imagens do atentado terrorista em Londres em 2005 foram feitas por meio de telefones celulares, tanto imagens fixas como vídeos. O mesmo aconteceu com o Tsunami na Ásia. Hoje no Iraque, as agências de notícias não enviam mais correspondentes e optaram por ensinar pessoas do lugar, que não somente falam o idioma, mas também têm as credenciais para estarem presentes nos locais necessários aos quais provavelmente um ocidental não teria acesso.? (MEYER, 2006).

Não vejo nenhum problema em relação ao “jornalismo-cidadão”. Claro que algumas ressalvas devem ser feitas e alguns - talvez muitos cuidados tomados. Mas será sempre maior a quantidade de notícias que chegará à imprensa feita por amadores e leitores do que aquela produzida por fotojornalistas. Até porque eles não podem estar o tempo

\footnotetext{
${ }^{7}$ Tradução livre do original: "Como muchos recordarán, las primeras y más importantes imágenes del atentado terrorista en Londres en el 2005 fueron todas tomadas con teléfonos celulares tanto en video como en foto fija. Lo mismo ocurrió con el Tsunami en Asia. Hoy en Irak, las agencias de noticias han dejado de enviar corresponsales y han optado por entrenar a gente local, que no sólo habla el idioma sino que tiene las credenciales necesarias para estar presente en los lugares precisos y a los cuales, probablemente, un homólogo occidental, no tendría acceso.”
} 
todo em todos os lugares. Claro que a questão do profissionalismo, da técnica do fotojornalista, continua pertencendo ao profissional preparado para isso. Mas a notícia quente, o fato, pode muito bem ser transmitido por um amador. Quem se insurge contra isso ou está de má fé ou é incompetente.

O que menos interessa ao destinatário é o autor, com a condição de que a foto seja imediata. Isto significou a proliferação de imagens tanto jornalísticas quanto artísticas para as agências internacionais de imagem. E com isso, corre-se o risco de saturação e de bloqueio cognitivo, uma espécie de aporia perversa: há muitas imagens, mas se torna cada vez mais difícil escolher a imagem necessária. Por exemplo, no caso da fotografia para os meios informativos, o transfert do fotógrafo para o jornalista da redação, a muita distância do acontecimento, a urgência do tempo em que manda para a agência a fim de não retardar a circulação de imagens geram os riscos de extrapolar ae manipular a interpretação da realidade, forçando-os a utilizar a primeira imagem de uma longa série e não necessariamente a melhor, nem a mais pertinente, reforçando com isso o estereótipo social e cultural a uma grande velocidade de difusão globalizada. (VILCHES, 2006, p.163).

Como vimos, o problema não é a alta produção, mas o mau uso feito das imagens produzidas numa falsa busca de urgência, de rapidez de tempo real. Moraes (2006, p.10) adverte que "a mitologia do tempo real impulsiona a difusão de repertório excessivos e a concentração de riqueza e poder".

Tivemos e temos vários exemplos disso. Ou seja, ao espetacularizar a notícia, torno forma e conteúdo idênticos. Eu tomo a encenação como fato real. “A imprensa informa pouco, mas diverte bastante” (COLO; ESTÈVE; JACOB, 2005, p.44).

Mas o que acontece é que cada vez mais eu preciso me superar na encenação. O que seria essa banalização: as coisas reinam sozinhas enquanto são jovens e acabam se desgastando e se recriando também sozinhas. O que domina nossa sociedade hoje é justamente essa idéia de espetáculo: não há outra coisa para ser. As imagens divulgadas pela mídia não são apenas representações, mas também promessas. 


\section{Considerações finais}

O que discutimos aqui são dois momentos distintos do fazer e entender o que é notícia. De um lado, a imagem-notícia, na qual o fotojornalista se assume como tal, como alguém que deve trazer informação via imagem. Aquele que escreve com a fotografia, com a luz; e de outro, o fotógrafo que não assume sua responsabilidade em informar. Preocupado apenas com a estética, como se isso fosse possível, faz do jornalismo imagético uma informação esquizofrênica. É o culto do eu, do fotógrafo que vira grife e não do trabalho que se sobrepõe a ele. Já se foi a época em que nem sabíamos qual era a cara do fotógrafo, hoje ele aparece mais do que as próprias fotos. Virou espetáculo, personagem, assim como sua imagem. Portanto, uma mancha vazia!

\section{Referências}

COLO, Olivia; ESTÈVE, Wilfrid; JACOB, Mat. Photojournalisme, à la croisée des chemins. Paris: Marval et CFD éditeur, 2005.

D’AUTILIA, Gabrielle. L'indizio e la prova - la storia nella fotografia. Milano: Bruno Mondatori, 2005.

DEBORD, Guy. Sociedade do espetáculo, Rio de Janeiro: Contraponto, 1997.

MARRA, Claudio. Le idee della fotografia: la riflessione teorica dagli anni sessanta ad oggi. Milano: Bruno Mondatori, 2001.

MARZO, Jorge Luis (Org.). Fotografia y activismo. Barcelona: Gustavo Gili, 2006. 
MEYER, Pedro. Disponível em: < http://zonezero.com/editorial/ enero06/january06.html>. Acesso em: maio 2006.

MORAES, Dênis (Org.). Sociedade midiatizada. Rio de Janeiro: Mauad, 2006.

PERSICHETTI, Simonetta; TRIGO, Thales (Org.). Hélio Campos Mello. Coleção Senac de Fotografia. São Paulo: Senac, 2003, v.2.

SOUSA, Jorge Pedro. Uma história crítica do fotojornalismo ocidental. Florianópolis: Letras Contemporâneas, 2000.

VILCHES, Lorenzo. Migrações midiáticas e criação de valor. In: MORAES, Dênis (Org.). Sociedade midiatizada. Rio de Janeiro: Mauad, 2006. 